\title{
Regular and Problematic Leisure-Time Internet Use in the Community-Results from a German Population-Based Survey
}

\author{
Manfred E. Beutel, M.D.,' Elmar Brähler,' Heide Glaesmer, ${ }^{2}$ Daria J. Kuss, M.A.,'
} Klaus J. Wölfling, D.Psych., and Kai W. Müller, D.Psych.'

\begin{abstract}
In our study, we attempted to identify systematically the use of Internet applications in the German population in order to derive risk factors for problematic use. In a representative survey of the German population, we queried 1,401 women and 1,111 men between the ages of 14 and 94 years by specific questions and standardized questionnaires on depression, anxiety (HADS), and depersonalization (CDS-2). The majority of the German population $(55 \%)$ used the Internet in their leisure time. Users were younger and had a higher socioeconomic status (education, employment, income). Leisure-time use included e-mail and information search, as well as shopping. Chatting, online communities, games and sex were domains of young, mostly male adults. Overall, 9.3\% reported at least one negative consequence of Internet use, especially neglect of recreational activities and problems with family/partner, work or education, and health. Problematic use was associated with longer average daily online times, avoidance of negative emotions, preference for certain applications (gaming, gambling, online sex) and an increased rate of depersonalization. The extent of Internet use per se is not sufficient as an addiction criterion and other negative consequences; rather, specific adverse consequences need to be identified. If the Internet is used excessively to cope with negative affect states and alternative means of coping (e.g., social support, health-promoting behavior) are diminished, a vicious cycle may ensue with increasing stress and reliance on the reinforcing properties of certain online activities that may finally lead to addictive behavior.
\end{abstract}

\section{Introduction}

W

HILE THE INTERNET HAS DRAMATICALly CHANGED WORK and leisure-time communication and interaction on a worldwide basis, its opportunities and hazards have remained issues of debate. The Internet provides almost unlimited opportunities as an indispensible source of information, education and business, shopping, travelling, or health-care issues. ${ }^{1}$ Already in 1999, however, Young has pointed out the addictive potential of different types of Internet use, for example, "cybersexual and cyber-relational addiction," "net compulsions," "information overload," and "computer game addiction." ${ }^{2}$ The lack of consensus regarding the classification of problematic Internet use is related to both the paucity of data and the myriads of Internet applications. It has been surmised that some Internet applications are more problematic than others. In a survey of mental-health professions, ${ }^{3}$ adult clients presenting with an Internet problem were characterized by addiction to child or adult pornography, young clients to gaming and gambling. Shaw and Black ${ }^{4}$ recently defined Internet addiction as "excessive or poorly controlled preoccupations, urges or behaviors regarding computer use and Internet access that lead to impairment or distress" (p. 353). In spite of recent pleas to include Internet addiction in the forthcoming DSM-V, it has remained an issue of debate if this is a genuine disorder specifically triggered by the Internet or whether the technology merely constitutes convenient means of acting upon other addictions (e.g., pathological gambling) or behavior problems.

Internet addiction has been associated with major depression, anxiety, personality disorders, ADHS, and substance abuse. ${ }^{4-8}$ In a small sample of outpatients, weekly hours on the Internet were correlated with dissociative experiences and disruption of family life. ${ }^{6}$ Among the predispositions of

\footnotetext{
${ }^{1}$ Ambulanz für Spielsucht, Klinik für Psychosomatische Medizin und Psychotherapie, Universitätsmedizin Mainz, Mainz, Germany.

${ }^{2}$ Selbständige Abteilung für Medizinische Psychologie und Medizinische Soziologie, Universitätsklinikum Leipzig AöR, Department für Psychische Gesundheit, Leipzig, Germany.
} 
Internet addiction, the male gender stands out. Other characteristics include social inhibition, ${ }^{9}$ low self-esteem and external locus of control, ${ }^{10}$ deficits in social skills, ${ }^{11}$ sensation seeking, low impulse control, and hostility. ${ }^{12}$ In our specialized outpatient clinic, we found a vicious cycle of attempts to cope with social phobia and depression by excessive Internet use, which in turn led to further depression, social anxiety, and performance failure. ${ }^{13}$ However, few epidemiological studies have been conducted. Internet use has been assessed in heterogeneous ways, ${ }^{14}$ based on highly selected convenience samples (online surveys, predominantly students or young adults). International studies have estimated a prevalence of $3 \%$ to $5 \%$ for youth and young adults; ${ }^{15}$ higher figures have been reported in Southeast Asia. ${ }^{5}$ In a German online survey, $3.2 \%$ of 7,089 participants were characterized as addicted to the Internet. ${ }^{16}$ In a recent online study with 1,319 young adults, those addicted to the Internet $(N=18$, $1.2 \%$ ) had increased depression and engaged frequently in online sex, gaming, communities, or chatting. ${ }^{17}$

So far, only one representative community telephone survey ${ }^{18}$ has been reported with 2,513 adults in the United States (response rate of $56.3 \%$, oversampling women and older respondents). Of the regular Internet users (68.9\%), 13.7\% to $3.7 \%$ endorsed specific negative consequences, found it hard to stay away from the Internet, stayed online longer than intended, concealed leisure-time use, escaped problems, engendered negative effects on their relationships, and were preoccupied with the Internet when offline. Unlike previous studies, we attempted to identify systematically the use of Internet applications in the general population answering the following questions: (a) who has access to the Internet in leisure time (according to gender, age, education); (b) which applications are used to what extent in the general population; and (c) which negative consequences arise from Internet use and which risk factors can be identified?

\section{Methods}

\section{Study participants}

This study is based on a representative survey of the German population recruiting a total of 1,401 women and 1,111 men (Table 1) between the ages of 14 and 94 years by July 2009. Data were collected by USUMA (Unabhängiger Service für Umfragen, Methoden und Analysen Berlin) based on 258 sample points in Eastern and Western parts of Germany. The survey followed ADM guidelines. ${ }^{19}$ The procedure was approved by the ethics committee of the University of Leipzig. Participants were questioned by trained interviewers in their homes (face-to-face-interviews); they filled out questionnaires independently in the presence of the interviewer. Households were selected by the random-route procedure. The target person in each household was also selected randomly. Potential participants were contacted by telephone first. The sample was representative for the total German population (as confirmed by ADM-sample). Of the initial sample, $54.9 \%$ could be contacted; this is well in the range of quotas of other representative community samples. ${ }^{19}$ No incentives were offered for study participation.

The mean age was 49.5 years. For further analysis, the sample was divided into six age groups with comparable proportions (Table 1). More than $49 \%$ of the participants were married, and $56 \%$ lived in a partnership. The vast majority
(83\%) had less than high-school education, and the monthly household income was mostly less than $€ 2,500$. Seventy-six percent reported a religious affiliation. Almost half were fullor part-time employed, and 30\% were on pension. The majority $(77 \%)$ lived in the Western states of Germany; $86 \%$ lived in urban areas $(>20,000$ inhabitants). Women were more frequently $(p<0.001)$ widowed than men $\left(\chi^{2}[d f=5]=28.7\right)$, had a lower level of education $\left(\chi^{2}[d f=3]=23.9\right)$ were less frequently full-time and more part-time employed $\left(\chi^{2}\right.$ $[\mathrm{df}=4]=22.6$.

\section{Questionnaires}

We inquired about Internet use "only during leisure time," "for leisure time, as well as for work," "for work only," or "not at all". Average hours of leisure time Internet use was assessed separately per weekday and per weekend, holiday or vacation by two open items. Frequency of leisure time use was differentiated as "daily," "2-3 times per week," "once per week," "once per month," "less." The average duration of online activities was assessed separately for weekdays and weekends/holidays ("less than 1 hour, 1-2, 2-4, 4-6, >6 hours"). Use of the Internet was ascertained by a dichotomous item ("yes" /"no") regarding online games, shopping, chatting, e-mails, online sex, gambling, communities, and information search ("never, rarely, frequently, very frequent$\left.l y^{\prime \prime}\right)$. Negative consequences of Internet use were also assessed ("yes"/"no"). Participants endorsing "yes" were asked about "problems with work, school, training, family/partnership"; "financial problems"; "neglect of recreational activities," and "health-related problems (lack of sleep, nutrition)". An additional question (5-point scale) assessed the use of the Internet to cope with negative affect (boredom, anger, sadness) by means of engaging in Internet activities.

The CDS-2 is a brief two-item version of the Cambridge Depersonalization Scale identifying patients with clinical depersonalization (DP) (cut-off $\geq 3$, sensitivity $=78.9 \%$, specificity $=85.7 \%$ ) with high reliability (Cronbach's $\alpha=0.92$ ). Items, for example "Out of the blue, I feel strange, as if I were not real or as if I were cut off from the world," are rated according to frequency over the last 2 weeks ("Not at all," "Several days," "More than half the days," "Nearly every day"). ${ }^{20}$ The Hospital Anxiety and Depression Scale (HADS) ${ }^{21}$ assesses anxiety and depression with seven items each.

\section{Statistical analysis}

Univariate and multivariate parametric and nonparametric statistics were performed by SPSS Version 17.0. As this was an exploratory study, no Bonferroni corrections were performed.

\section{Results}

\section{Leisure time access: Users and nonusers} of the Internet

A total of 1,381 participants (55\%) used the Internet in their leisure time, including 527 (21\%) who also used for it for their job. Another $36(1.4 \%)$ only used it for their job. A total of $1,094(43.6 \%)$ did not use the Internet. Table 1 compares leisure-time users and nonusers. For comparisons between users and nonusers, participants who only used the Internet at work were omitted. 
Table 1. Study Participants: Leisure-Time Users $(N=1,381)$ and Nonusers $(N=1,094)$ OF the Internet

\begin{tabular}{|c|c|c|c|c|c|c|}
\hline & Participants ( $\mathrm{N}=2,475)$ & $\mathrm{N}$ & $\%$ & User* $(\%)$ & Non-user (\%) & Overall $\chi^{2}$ leffect size \\
\hline \multirow{6}{*}{ Age (years) } & $<25$ & 256 & 10.3 & 89.5 & 10.5 & \\
\hline & $25-34$ & 353 & 14.1 & 84.1 & 15.9 & \\
\hline & $35-44$ & 416 & 16.8 & 76.9 & 23.1 & \\
\hline & $45-54$ & 424 & 17.7 & 67 & 33 & \\
\hline & $55-64$ & 400 & 16.1 & 42.3 & 57.7 & $821.8^{* *}$ \\
\hline & $>65$ & 626 & 25.0 & 13.1 & 86.9 & $C V=0.58$ \\
\hline \multirow[t]{2}{*}{ Sex } & Male & 1111 & 44.2 & 60.3 & 39.7 & 21.8 \\
\hline & Female & 1401 & 55.8 & 50.7 & 49.3 & $\eta=0.09$ \\
\hline \multirow[t]{4}{*}{ Marital status } & Married, living together & 1222 & 49.4 & 56.8 & 43.2 & \\
\hline & Married, separated; divorced & 308 & 12.5 & 54.2 & 45.8 & \\
\hline & Single & 641 & 26 & 75.7 & 24.3 & 334.4 \\
\hline & Widowed & 304 & 12.2 & 11.5 & 88.5 & $C V=0.37$ \\
\hline \multirow[t]{2}{*}{ Living with partner } & Yes & 1402 & 6.5 & 58.4 & 41.6 & 15.6 \\
\hline & No & 1094 & 44.1 & 51.4 & 48.6 & $\eta=0.08$ \\
\hline \multirow[t]{4}{*}{ Education } & $<10$ grade & 1099 & 44.2 & 34.5 & 65.5 & \\
\hline & 10th grade & 953 & 38.6 & 67.3 & 32.7 & \\
\hline & Student & 256 & 10.4 & 85.6 & 14.4 & 402.9 \\
\hline & College/university & 167 & 6.8 & 85 & 15 & $C V=0.40$ \\
\hline \multirow[t]{7}{*}{ Occupation } & Full-time, $>34$ hours & 928 & 36.9 & 76.9 & 23.1 & \\
\hline & Part-time, $15-34$ hours & 278 & 11.1 & 74.1 & 25.9 & \\
\hline & Unemployed & 195 & 7.8 & 45.1 & 54.9 & \\
\hline & Homekeeper & 152 & 6.1 & 50.7 & 49.3 & \\
\hline & Retirement & 764 & 30.4 & 15.6 & 84.4 & \\
\hline & School/university & 136 & 5.4 & 93.4 & 6.6 & 852.3 \\
\hline & Other & 59 & 2.3 & 84.7 & 15.3 & $C V=0.59$ \\
\hline \multirow{2}{*}{ Place of residence } & West & 1905 & 77 & 59.1 & 40.9 & 36.7 \\
\hline & East & 570 & 23 & 44.7 & 55.3 & $\eta=0.12$ \\
\hline \multirow[t]{3}{*}{ Income } & $<€ 1,250 /$ month & 598 & 24.9 & 36 & 64 & \\
\hline & $€ 1,250-2,500 /$ month & 1251 & 52.0 & 53.5 & 46.5 & 255.2 \\
\hline & $>€ 2,500 /$ month & 556 & 23.1 & 82.2 & 17.8 & $C V=0.33$ \\
\hline
\end{tabular}

*Persons who use the Internet only for work-related purposes $(N=37)$ were excluded from analyses. ${ }^{* *}$ All $\chi^{2}$ tests, $p<0.001$.

With a mean age of $40.2(S D=14.5)$ years, Internet users were significantly younger than nonusers $(M=61 ; S D=15.9$; $t[2319]=33.4, p=0.000)$. Up to the age group of $45-54$ years, the majority reported using the Internet. Above 55 years, the proportion of nonusers exceeded the users. Overall, a higher proportion of males used the Internet compared to females. While three-quarters of single people used the Internet, only $11.5 \%$ of the widowed did so. Moreover, the presence of a partnership and higher education were associated with Internet use: more than $85 \%$ of students and participants with a college or university degree used the Internet compared to about one third of those below 10th grade of education. Whereas three-quarters of the employed used the Internet for leisure time, only half of the homekeepers, less than half of the unemployed, and one sixth of the retired participants were users. Residence in the Western states of Germany was also associated with Internet use; those in the highest income group had access more than twice as frequently as those with the least income.

\section{Internet applications and online times}

Table 2 shows Internet applications in declining order across age groups for the total sample, and separately for men and women. Almost all participants used the Internet for e-mail and information search, and the majority reported shopping and chatting. There was no difference regarding use of e-mails and online gambling across age groups. The majority continued to use information search and shopping over 65 years. Chatting, online communities, games, and sex were domains of young adults ( $<35$ years). Information search, shopping, and chatting were used equally by men and women. All other applications, particularly online sex, gambling, and games were used by men at a higher rate.

We compared users and nonusers of each Internet application regarding avoidance of negative emotions. This was the case for all but for online search. Avoidance of negative emotions was most pronounced $(p<0.001)$ in online gambling, sex, communities, and chatting.

As assessed by the open question, on the average, the Internet was used longer during the week (2.9 hours, $S D=3.1)$ than on weekends, holidays, or vacations $(2.4, S D=2.1$ hours; ANOVA $F[1,790]=24.8, p=0.000$ ). Overall, $3.4 \%$ made use of the Internet for more than 4 hours per day, $56.5 \%$ had online times between 1 and 4 hours, and $40.1 \%$ used it less than 1 hour per day.

\section{Negative consequences of Internet use and their determinants}

Table 3 differentiates negative consequences of Internet use according to gender. Overall, $9.3 \%(N=129)$ of Internet users reported at least one and $3.5 \%(N=48)$ more than one negative consequence of Internet use. Neglect of recreational activities was endorsed by $5.2 \%$, followed by problems and 


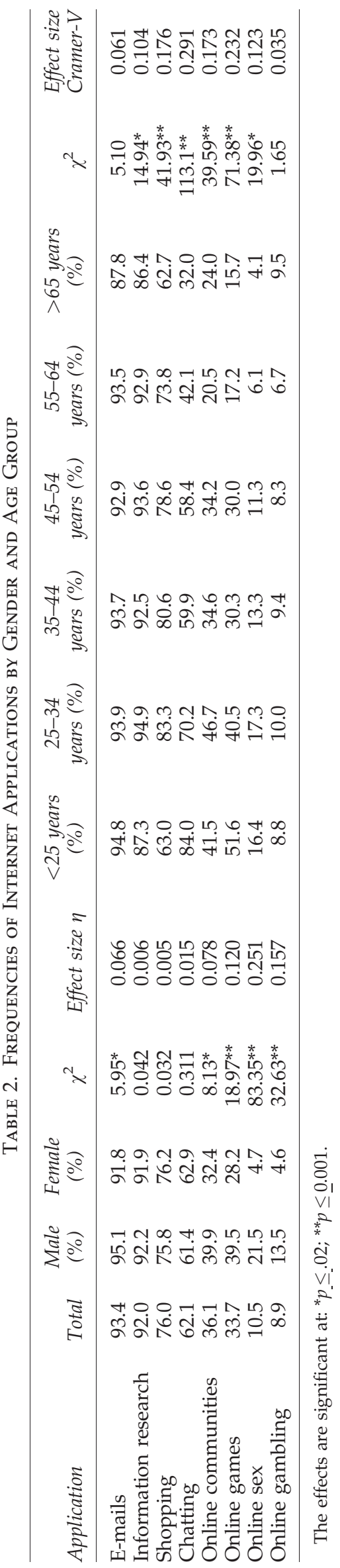

neglect of family/partner/friends, problems with work or education and health; financial problems were rarely reported. Men (13.6\%) reported highly significantly more negative consequences than women $(7.4 \%)$; this pertained to recreational activities and problems with work particularly.

Compared to normal users, problematic users with at least one negative consequence of Internet use $(N=129)$ were younger $(M=36$ vs. $M=50$ years; $t[151]=10.9 ; p \leq 0.000)$. They were more frequently male $\left(\chi^{2}[2]=10.4 ; p<0.00 \overline{1}\right)$ and single $\left(\chi^{2}[2]=12.3 ; p<0.01\right)$. Concerning online time, the majority $(73.6 \%)$ of problematic Internet users spent between 1 and 4 hours per day (compared to $54.6 \%$ of the normal users). A total of $14.7 \%$ of the problematic users spent more than 4 hours per day online in contrast to $2.2 \%$ of the normal users, illustrating that problematic Internet use is associated with significantly longer online times $\left(\chi^{2}[4]=102.6\right.$; $p \leq 0.001)$. Problematic users reported more avoidance of negative emotions ( $M=1.7$ vs. $M=0.7)$ compared to regular users $(t[148]=10.5, p \leq 0.001)$. There was no difference regarding anxiety or depression. Twice as many problematic users $(6.3 \%)$ suffered from depersonalization compared to the regular users $\left(3.2 \% ; \chi^{2}[1]=3.4, p=0.067\right)$. Depersonalization was significantly $(p<0.001)$ correlated with anxiety and depression $(r=0.3)$, but not with average online time.

\section{Discussion}

In line with a previous American survey, the majority of the German population (55\%) used the Internet in their leisure time, including $21 \%$ who also used it for their job. Few $(1.4 \%)$ only used it for their job, and $43.6 \%$ did not use the Internet at all. Up to the 45-54-year age group, the majority reported using the Internet. Overall, users were younger, more frequently employed, and residents of the Western states of Germany. As surmised, Internet use was associated with higher social status (income, education).

E-mail, information search, and shopping were used by the majority across the life span. Chatting, online communities, games, and sex were domains of young adults ( $<35$ years); there was no age effect regarding online gambling. Online sex, gambling, and games were used by a higher proportion of men. Along with gambling, online communities were strongly related to avoidance of problems and negative affect. Overall, the great majority reported being online for up to 2 hours per weekday. Average online times were significantly higher during the week than during weekends, holidays, or vacations. In line with previous research, online time was significantly higher in younger participants and in males. ${ }^{7,15,17}$ Overall, 9.3\% of Internet users reported at least one negative consequence of Internet use. The proportion of problematic use was almost twice as high among men (13.6\%) than among women $(7.4 \%)$, particularly neglecting recreational activities and problems with work. Other negative consequences were problems with and neglect of family, partner, and friends, and health-related and financial problems.

The average weekday online time of problematic users was significantly higher than other users. They were younger ( $M=36$ vs. $M=50$ years) and more frequently male and single than normal users. Further analyses supported the validity of problematic use. Problematic Internet users were more frequently online in order to avoid negative emotions. While there was no effect on anxiety and depression (HADS), 
Table 3. Negative Consequences of Internet Use According to Gender

\begin{tabular}{lccccccc}
\hline Leisure time Internet Users (N=1382) & $\mathrm{N}$ & $\%$ & Male (\%) & Female (\%) & Overall $\chi^{2}$ & $\mathrm{p}$ & Effect size $\eta$ \\
\hline Neglect of recreational activities* & 72 & 5.2 & 6.9 & 3.7 & 7.2 & 0.007 & 0.072 \\
Problems with family/partner & 44 & 3.2 & 3.9 & 2.5 & 2.0 & 0.152 & 0.039 \\
Neglect of friends/partner & 33 & 2.4 & 2.5 & 2.3 & 0.12 & 0.727 & 0.009 \\
Problems with work/education & 17 & 1.2 & 1.9 & 0.6 & 5.4 & 0.02 & 0.063 \\
Health-related problems & 16 & 1.2 & 1.3 & 1.0 & 0.39 & 0.534 & 0.017 \\
Financial problems & 10 & 0.7 & 0.7 & 0.7 & 0.009 & 0.925 & 0.003 \\
Total** & 129 & 9.3 & 13.6 & 7.4 & 17.4 & 0.000 & 0.083 \\
\hline
\end{tabular}

*Multiple answers can be endorsed. ${ }^{* *}$ At least one negative consequence.

problematic use was also associated with an increased rate of depersonalization.

Unlike previous studies, which were based on convenience samples with limited age range (usually young people, Internet-based surveys), this study is a representative population-based survey with a range from 14 to 92 years. Our findings differentiate benefits and hazards of Internet use on the basis of the German population. As we show, persons with higher socioeconomic status have more access to the Internet and use its numerous applications and opportunities (e-mail, information search, shopping) across all age groups. Promoting and encouraging access may thus open chances for information, communication, and participation to underprivileged groups (e.g., unemployed, widowed).

On the other hand, a substantial proportion $(9.3 \%)$ reported negative consequences of excessive use compromising recreational activities, health, work, and social relationships. As problematic online use was associated with excessive online time and with certain applications preferred by men (especially gaming, gambling, online sex), again young men were at greatest risk.

It may be seen as a limitation that distinctions between addictive and non-addictive use cannot be made on the basis of our data. Minimizing negative consequences is one characteristic of addiction limiting its identification addiction by self-report. On the other hand, the pattern of results substantiates the negative consequences specified. The amount of Internet use per se is not a sufficient criterion for addiction. Rather, specific adverse consequences need to be identified. An important factor in the development of problematic use may pertain to the use of certain Internet applications to cope with negative affect. Excessive use of the Internet may also foster depersonalization; this may be stronger for certain applications (e.g., online role-play games) than for others. Due to the cross-sectional nature of the study, however, it cannot be determined whether the higher rate of depersonalization among problematic users results from excessive use or whether persons with DP are more prone to use the Internet. If the Internet is used excessively to cope with negative affect states and alternative means of coping (e.g., social support, health-promoting behavior) are reduced, a vicious cycle may ensue with increasing stress and reliance on the reinforcing properties of certain online activities that may finally lead to addictive behavior.

\section{Disclosure Statement}

No competing financial interests exist.

\section{References}

1. Rojas H, Puig-i-Abril E. Mobilizers mobilized: Information, expression, mobilization and participation in the digital age. Journal of Computer-Mediated Communication 2009; 14:902-27.

2. Young KS. (1999) Internet addiction: Symptoms, evaluation and treatment. In VanDeCreek L, Jackson TL, eds. Innovations in clinical practice. Vol. 17. Sarasota, FL: Professional Resource Press.

3. Mitchell KJ, Wells M. Problematic Internet experiences: Primary or secondary presenting problems in persons seeking mental health care? Social Science \& Medicine 2007; 65:1136-41.

4. Shaw M, Black DW. Internet addiction-Definition, assessment, epidemiology and clinical management. CNS Drugs 2008; 22:353-65.

5. Block JJ. Issues for DSM-V: Internet addiction. American Journal of Psychiatry 2008; 165:306-7.

6. Bernardi S, Pallanti S. Internet addiction: A descriptive clinical study focusing on comorbidities and dissociative symptoms. Comprehensive Psychiatry 2009; 50:510-6.

7. Ha JH, Yoo HJ, Cho IH, et al. Psychiatric comorbidity assessed in Korean children and adolescents who screen positive for Internet addiction. Journal of Clinical Psychiatry 2006; 67:821-6.

8. Reirdan J. Internet-depression link? American Psychologist 1999; 54:718-82.

9. Moody EJ. Internet use and its relationship to loneliness. CyberPsychology \& Behavior 2001; 4:393-401.

10. Kim J, Haridakis PM. The role of Internet user characteristics and motives in explaining the three dimensions of Internet addiction. Journal of Computer-Mediated Communication 2009; 14:988-1015.

11. Ghassemzadeh L, Shahraray M, Moradi A. Prevalence of Internet addiction and comparison of Internet addicts and non-addicts in Iranian high schools. CyberPsychology \& Behavior 2008; 11:731-3.

12. Yen JY, Ko $\mathrm{CH}$, Yen $\mathrm{CF}$, et al. Psychiatric symptoms in adolescents with Internet addiction: Comparison with substance use. Psychiatry \& Clinical Neurosciences 2008; 62: 9-16.

13. Beutel ME, Hoch C, Wölfling K, et al. Diagnostische und klinische Merkmale der Computerspiel- und Onlinesucht am Beispiel der Inanspruchnahme einer Spielsuchtambulanz. Zeitschrift für Psychosomatische Medizin und Psychotherapie; in press.

14. Wölfling K, Müller KW, Beutel ME. Skala zum Computerspielverhalten (CSV-S) - Psychometrische Kennwerte eines klinisch-diagnostischen Instruments zum pathologischen Computerspielverhalten. Psychotherapie, Psychosomatik, Medizinische Psychologie; in press. 
15. Batthyány D, Müller KW, Benker F, et al. Computerspielverhalten: Klinische Merkmale von Missbrauch und Abhängigkeit. Wiener Klinische Wochenschrift 2009; 121:502-9.

16. Hahn A, Jerusalem M. (2001) Internetsucht: Jugendliche gefangen im Netz. In Raithel J (Hrsg) Risikoverhaltensweisen Jugendlicher. Erklärungen, Formen und Prävention. Opladen, Germany: Leske \& Budrich, pp. 1-21.

17. Morrison CM, Gore H. (2010) The relationship between excessive Internet use and depression: A questionnaire-based study of 1,319 young people and adults. Psychopathology 2010; 43:121-6.

18. Aboujaoude E, Koran LM, Gamel N, et al. Potential markers for problematic Internet use: A telephone survey of 2,513 adults. CNS Spectrums 2006; 11:750-5.

19. Koch A. (1997) ADM-Design und EinwohnermelderegisterStichprobe. Stichproben bei mündlichen Bevölkerungsumfragen. In Gabler S, Hoffmeyer-Zlotnik JHP, Krebs D, eds Stichproben in der Umfragepraxis. Opladen, Germany: Westdeutscher Verlag, pp. 99-116.
20. Michal M, Zwerenz R, Tschan $R$ et al. Screening for depersonalization-derealization with two items of the Cambridge Depersonalization Scale. Psychotherapie, Psychosomatik, Medizinische Psychologie 2010; 60:175-9.

21. Hinz A, Schwarz R. Anxiety and depression in the general population: normal values in the Hospital Anxiety and Depression Scale. Psychotherapie, Psychosomatik, Medizinische Psychologie 2001; 51:193-200.

Address correspondence to: Daria J. Kuss

Ambulanz für Spielsucht

Klinik für Psychosomatische Medizin und Psychotherapie

Universitätsmedizin Mainz

Untere Zahlbacher Straße 8

55131 Mainz, Germany

Email: kuss@uni-mainz.de 


\section{AUTHOR QUERY FOR CYBER-2010-0199-BEUTEL_1P}

AU1: Please confirm degrees present are correct, and provide highest academic degree for Brahler and Glaesmer. 